\title{
Corrigendum to "Assessing blue and green water utilisation in wheat production of China from the perspectives of water footprint and total water use" published in Hydrol. Earth Syst. Sci., 18, 3165-3178, 2014
}

X. C. Cao ${ }^{1,2}$, P. T. Wu ${ }^{1,2}$, Y. B. Wang ${ }^{1}$, and X. N. Zhao ${ }^{2}$

${ }^{1}$ College of Water Resources and Architectural Engineering, Northwest A \& F University, Yangling, Shaanxi, 712100, China

${ }^{2}$ Institute of Water Saving Agriculture in Arid regions of China, Northwest A \& F University, Yangling,

Shaanxi, 712100, China

Correspondence to: P. T. Wu (gjzwpt@vip.sina.com)

We would like to point out that there is a mistake in Eq. (1).

This is the correct equation:

$P_{\mathrm{e}}=\left\{\begin{array}{ll}P(4.17-0.02 P) / 4.17, & P<83 \\ 41.7+0.1 P, & P \geq 83\end{array}\right.$. 